\title{
Toward Active Reflexivity: Positionality and Practice in the Production of Knowledge
}

Jessica Soedirgo, University of Toronto

Aarie Glas, Northern Illinois University

ABSTRACT How should scholars recognize and respond to the complexities of positionality during the research process? Although there has been much theorizing on the intersectional and context-dependent nature of positionality, there remains a disjuncture between how positionality is understood theoretically and how it is applied. Ignoring the dynamism of positionality in practice has implications for the research process. This article theorizes one means of recognizing and responding to positionality in practice: a posture of "active reflexivity." It outlines how we can become actively reflexive by adopting a disposition toward both ongoing reflection about our own social location and ongoing reflection on our assumptions regarding others' perceptions. We then articulate four strategies for doing active reflexivity: recording assumptions around positionality; routinizing and systemizing reflexivity; bringing other actors into the process; and "showing our work" in the publication process.

I do remain puzzled by how to teach students to be reflexive. Is reflexivity a skill? A set of methods that can be taught? If so, what are the methods of reflexivity?

Wanda Pillow $(2003,171)$

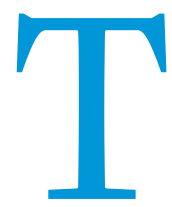

here is a growing consensus across political science that positionality matters. Qualitative-interpretivist scholars, for instance, have written about the importance of reflexivity in interviewing and ethnography (Fujii 2017; Shehata 2006). Similarly, scholars in the quantitative-positivist tradition have considered the ways that interviewer identity affects survey results (Adida et al. 2016; Davis 1997). This growing recognition has been accompanied by much theorizing on the intersectional and context-dependent nature of positionality. However, less has been written in political science about the practice of reflexivity within research processes. There remains a disjuncture between how positionality is understood theoretically and how it is applied.

How should scholars recognize and respond to the complexities of positionality during the research process? We approach this question through our experiences as qualitative researchers conducting interviews for very different projects: Jessica investigating

Jessica Soedirgo iD is a PhD candidate (ABD) in political science at the University of Toronto. She can be reached at jessica.soedirgo@utoronto.ca.

Aarie Glas is assistant professor of political science at Northern Illinois University. Hecan be reached at aglas@niu.edu. conflict involving very small groups (Soedirgo 2018) and Aarie exploring governance practices within regional organizations (Glas 2017; 2018). Despite our academic appreciation of positionality, we both found it difficult to incorporate its dynamism into our research.

This article theorizes one means to recognize and respond to positionality in research practice. We advance a posture of what we term "active reflexivity." A posture, unlike a habit or a set of procedures, is an embodied disposition toward reflexivity as research is conducted-from design to data collection to interpretation. ${ }^{1}$ More narrowly, we see active reflexivity as a triple movement, consisting of ongoing interrogations of (1) our positionality; (2) how our positionality is read by others, given their own social location and the contexts in which we interact; and (3) the assumptions about our conclusions in the first two stages.

This article is structured in two parts. We begin by illustrating a gap between how positionality is described in theory and how it often is practiced. Here, we rely on our own research experiences alongside those of other scholars to highlight the challenges of doing reflexivity in the field. In the second part, we outline the foundations of being actively reflexive and offer four concrete strategies to do active reflexivity.

\section{POSITIONALITY IN PRACTICE}

When positionality is theorized, it is understood both epistemologically and ontologically as dynamic and context specific. This is well established within feminist literatures-and black feminist 
thought in particular-which highlight the intersectional nature of identity and power and the social structures in which they operate (Carbado 2013; Showden and Majic 2018, 112-16). As Crenshaw (1991), hooks (2014), and others have long documented, individuals simultaneously hold multiple identities that interact in contextualized ways. Our positionality is not reducible "fine-grained" and "valid" data (Cammett 2013, 140). Although Cammett's assumptions are certainly plausible, she does not indicate that she assessed whether shared religious identity operated according to her expectations. Given intersectionality, it is likely that the effects of religious identity did not always operate linearly. Proxy interviewing is only one example of a reflexivity

\section{A posture, unlike a habit or a set of procedures, is an embodied disposition toward reflexivity as research is conducted-from design to data collection to interpretation.}

to demographic characteristics (e.g., race, age, gender, and class); it also is informed by our personal and professional experiences, our political and ideological stances, and other aspects of our social biography, or "lifeworld" (Berger 2015, 220; Bernstein 1976; Thomas 2018; Yanow 2006). Our positionality does not neatly "translocate" from one context to another but instead is inherently contextual (Henry, Higate, and Sanghera 2009). The combination of qualities that is salient to our research experiences thus varies in relation to our participants and the contexts in which we operate (Fujii 2017).

To respond to positionality, researchers are instructed to be reflexive: to interrogate the effects of their social location across research interactions. This is seen increasingly as necessary to ensure the "accuracy" and "trustworthiness" of research, particularly in qualitative research (Berger 2015, 221; Schaffer 2016; Yanow 2014). As Shehata $(2006,247)$ underscores, we gain knowledge about the world only through our positionality. Therefore, we must assess how it impacts our interactions if we are to generate useful data about the world (Gunaratnam 2003; Sherif 2001; Yanow and Schwartz-Shea 2006). We mean this not in the positivist sense of uncovering objective truths "out there" but rather as a dynamic and contextualized approximation of how individuals understand the world around them and the researcher's role in the generation of that assessment. Relatedly, reflexivity increasingly is seen as a necessary component of ethical research. Fujii $(2017,23)$, for example, explains how being attuned to relational power dynamics can shape strategies for obtaining informed consent. Overall, paying attention to how positionality assists and constrains the cogeneration of knowledge can help scholars make each research interaction more fruitful.

Despite the importance of reflexivity and the theoretical consensus on the intersectional character of positionality, in practice, doing reflexivity is challenging. Many researchers who attempt to be reflexive-including the authors-understand their positionality in static terms and make general assumptions regarding its effects on their research. The difficulties of translating our theoretical understandings of reflexivity into research design and practice are illustrated by Cammett's (2013) interviewing strategy for her project on social-service provision by sectarian parties in Lebanon. Despite acknowledging the complexities of insider/outsider designations, her strategy of "proxy interviewing" involved "matching" interviewers and interviewees on a single identity category: religion. She matched on religious background because sectarian identity was salient in the post-civil war period and she assumed that in-group interviewers would have greater rapport with participants (Cammett 2013, 132). She concludes that proxy interviewing allowed her to obtain more that acknowledges researchers' identity, but does not actively unpack assumptions about how intersectional identities make interactions contingent and context specific.

Ignoring the contingency, dynamism, and specificity of positionality has implications for the research process, shaping research design, access to participants, data collection, and data interpretation. This reality was made clear to Aarie during his investigation of regional practices at the Association of Southeast Asian Nations (ASEAN) and the African Union (AU). Aarie is a relatively young, white, male Canadian researcher. At ASEAN, he found that his outsider status made possible access and rapport with officials. Most interview requests were met with positive, even enthusiastic responses, and interviewees were often generous with their time and candor.

Moving to the AU, Aarie assumed that his outsider status would be similarly advantageous and he designed a sampling strategy based on his experiences at ASEAN. Although perhaps naïve, his assumptions were not without foundation. The two organizations share similarities: both exude the aesthetics of diplomacy, have similar organizational structures, and are populated by well-educated and worldly professionals fluent in English. However, of the $30 \mathrm{AU}$ member-state embassies initially contacted for meetings in Addis Ababa, only four responded directly to his emails and calls; none agreed to a meeting. When Aarie spoke with North American and European officials working alongside the AU, many indicated that his assumptions about access were problematic. A white, foreign outsider was going to have difficulty gaining access to AU member-state officials, much less engaging in lengthy and candid conversations. After recognizing these obstacles, Aarie adapted his strategy of cold emailing and calling. He instead relied on a growing network of interlocutors, who assisted in making initial introductions with AU and member-state officials.

Aarie's experiences of ignoring the dynamism of positionality had two immediate effects: it hindered access to potential interviewees and made it more difficult to build "working relationships" with participants (Fujii 2017, 15). Not only does building a working relationship mean that researchers are better positioned to generate nuanced and meaningful data; it also allows them to treat participants with dignity and respect and thus work more ethically (Knott 2019). Aarie's lack of dynamic interrogation of his positionality not only necessitated changes to his research design and hindered his fieldwork; it also made it more challenging to adequately engage in ethical and meaningful relationships with participants.

Static assumptions about positionality also can shape how data are interpreted. For example, if a female researcher assumes 
that women interviewees will be more open to her without considering other dimensions of identity, she may read interviews given by men with greater skepticism (Riessman 1987). Jessica initially made these assumptions about insiders and outsiders when she analyzed interview data about the targeting of the minority Ahmadiyah sect by members of Indonesia's Sunni majority. this recognition to shape our research designs, interactions, and interpretations (Fujii 2017).

Building from this foundation of humility, being actively reflexive requires a dynamic, continual, and fluid interrogation of positionality in three interrelated ways. First, researchers must engage in ongoing reflection about their own positionality.

\section{Ignoring the contingency, dynamism, and specificity of positionality has implications for the research process, shaping research design, access to participants, data collection, and data interpretation.}

As a Christian woman of Chinese Indonesian heritage, her background placed her outside of the ethnic and religious majority. Given her focus on religious conflict, Jessica assumed that religion would be the most salient aspect of her identity. Although she did not share a religious identity with her participants, Jessica assumed that as a religious minority herself, Ahmadis would see her as an insider and Sunni Muslims would view her as an outsider. Because she presumed that religious identity would be most salient, she overlooked other dimensions of identity such as her ethnicity, gender, and class.

Jessica made assumptions about how her position as an insider or outsider shaped her interview data. She assumed other religious minorities would be more forthcoming whereas Sunni Muslims complicit in targeting Ahmadis would be less so. Consequently, when actors complicit in anti-minority activity told her that they mobilized against Ahmadiyah communities due to their insistence on being called Muslims and their conspicuous religious activity, Jessica read these quotes with a high level of skepticism. She thought that they were engaging in victim blaming to avoid articulating their "real" reasons for mobilization. After extended reflection, however, Jessica realized that these quotes were crucial for understanding why the Ahmadiyah-a group comprising less than $1 \%$ of the population-would be considered threatening despite their economic and political insignificance. If Jessica had continued assuming that insider/outsider dynamics worked in a particular way, she would have overlooked a key factor driving the phenomenon that she was studying.

Overall, despite the theoretical consensus that positionality is dynamic and reflexivity is essential, there remains a tendency for many scholars to rely on static assumptions about the nature of their positionality and its impact on research. As our experiences show, these assumptions come with risks: limiting access, hindering the development of good working relationships, and impeding our ability to generate knowledge. To mitigate the pitfalls of reflexivity in practice, we propose that researchers adopt a posture of active reflexivity. This requires being actively reflexive and pursuing a number of strategies to do active reflexivity.

\section{ACTIVE REFLEXIVITY}

Being actively reflexive starts with a recognition that social interactions are at the heart of social research. Given the particularities of context and the intersectional nature of positionality, scholars must accept that interpretations of positionality are always contingent and likely incomplete. The foundation of active reflexivity, then, is humility, meaning that we accept the complex, contingent, and human-ness of the research enterprise and allow
Second, and relatedly, researchers should reflect on how others are likely to perceive their positionality within research interactions. These appraisals are likely to be contingent, incomplete, or potentially problematic in unforeseen ways. Nevertheless, however complex the effects of positionality, we should commit to interrogating them. To this end, we suggest that researchers ask: How might I be "read" by my participants and interlocutors? Which factors are likely to influence our interactions before we meet? Which factors are likely to influence our interactions after we meet? How will I know if my assumptions played out in practice? Third, researchers should reflect on the assumptions made within their answers to these questions.

Taken together, these three levels of reflection constitute a foundational approach to being actively reflexive. This approach means attempting awareness not only of our positionality but also interrogating the inherent assumptions that we make of those effects-and to do so continually throughout the research process. Reflexivity, therefore, should occur even when researchers believe that they have understood and anticipated the effects of their positionality within their research interactions.

But how should researchers do active reflexivity? In addition to asking and answering the previous questions, we offer four strategies. Each arises from the foundation of humility, recognizing the contingent nature of knowing and responding to positionality (Pachirat 2015). These premises demand that we anticipate being incomplete or uncertain in our appraisals, that we explicitly incorporate mechanisms into our research to stimulate reflection and learning, and that we interrogate and make transparent our research processes and reflections on positionality in our publications (Jacobs and Büthe 2019, 12-13). Moreover, each strategy represents a commitment to continual reflection on the myriad aspects of positionality rather than doing reflexivity based on narrow self-conceptions or only during periods of perceived disjuncture between expectation and experience.

Our first strategy is to record-and record often. Scholars should document their reflections and assumptions throughout the research process, something usually discussed in fieldnote practices (Emerson, Fretz, and Shaw 2011). They should do so during the research design stage: interrogating and documenting assessments of their positionality, that of the presumptive other, and of the relationship between researcher and participants. These assumptions almost certainly will be challenged during the fieldwork and data-interpretation stages. However, making these assumptions explicit provides benchmarks for reflexivity at later stages, in terms of both incongruencies and congruencies between expectations and experiences. For example, Cramer 
Walsh's (2007) research design for studying race-dialogue programs in the United States illustrates the benefits of outlining preexisting assumptions. As she discusses in her methods appendix, she wrote detailed memos about how she expected research interactions to unfold, noting explicitly that her identity as a white person "undoubtedly influenced what [she] expected to influence of her ethnic and religious background on research but not that of her age. By identifying one of her blind spots, Jessica was subsequently more conscious of how her perceived youth could both facilitate and impede the development of working relationships. In some interviews, firmly identifying her age allowed her to be taken more seriously. At other times, leaning

\section{The foundation of active reflexivity, then, is humility, meaning that we accept the complex, contingent, and human-ness of the research enterprise and allow this recognition to shape our research designs, interactions, and interpretations (Fujii 2017).}

see" (Cramer Walsh 2007, 261). She notes that information from these early reflections proved "invaluable" in the analysis stage because immersion had desensitized her to important patterns of interaction in the data she collected. Recording our expectations of how we are likely to be seen-and why-is a first step for interrogating how our positionality may operate and impact our research. These records should be examined and updated throughout the data-collection and interpretation stages.

The second strategy is to systematize reflections into a preinterview record. This document should outline the expectations of positionality, the presumed effects, and the logic underlying these appraisals. That is, the document should explicate how the researcher expects positionality to operate in practice during research interactions. The document should be updated after each research interaction to record whether or not it unfolded according to expectations. This strategy may be particularly helpful when seeking to ascertain differences in the meanings of certain terms, which often are shaped by a researcher's disciplinary training. For example, one of the central findings of Aarie's interviewing was that the codified principle, "noninterference," had different meanings for officials in different regional organizations and that these understandings varied from his own (Oren $2015,316)$. From his position, this was not clear to him during the first interviews he conducted at ASEAN. It was only when he later reflected on his pre-interview records that he realized he had been assuming but misconstruing the meanings that interviewees ascribed to the term. The need to interrogate meanings of theoretical terms then became central to Aarie's interview process and his written records. Even if we perceive that an interaction unfolded as anticipated, it is still useful to consider why our expectations were met. Such a protocol compels reflection on the process of generating data and the meaning therein and assists us with reflexivity at later stages of interpretation.

The third strategy is to bring other individuals into the reflection process. Our own experiences and those of others make clear that there are limits to self-reflexivity (D'Arcangelis 2018). Colleagues and research assistants, for example, offer potential avenues for further reflexivity. Jessica brought her research assistant into the process of reflexivity to interrogate how she was being understood by her participants and with what effect (Syahar Banu and Soedirgo 2019). This shed light on dynamics of positionality that she had not considered. Her research assistant, for example, pointed out that Jessica's age likely impacted research interactions. This perception shaped responses given by interviewees, who likely viewed her as young and, therefore, naïve. As discussed, Jessica had interrogated the potential into expectations around her perceived naiveté made her less threatening and helped her build a working relationship with participants. Researchers also may consider asking their participants directly about their perceptions of positionality-as Cramer Walsh $(2007,261)$ did-to gain direct insight about what the other party is thinking. ${ }^{2}$ Sharing recorded reflections before and after interactions may allow researchers to draw on varied perspectives that reveal assumptions, push active reflection on how their positionality has been read, and consider how those readings have impacted their research in ways that we cannot do alone.

The fourth strategy suggests that, whenever possible, scholars should show their reflexivity work when publishing their research. There is value in making clear the assumptions guiding our scholarly interests; our work in the field; and when, why, and how we update and question our assumptions as our investigations progress. Fujii (2009, 32-44), for example, does this to ground her explanation of genocide in Rwanda. As she describes, her identity became a "focal point" in interviews and shaped her interactions in important ways, "open[ing] the door to questions that related directly to the kind of data [she] was seeking" (Fujii 2009, 35). Her level of transparency allows the reader to assess the quality of the data that her arguments rely on and sets a useful precedent for others to do the same (see also Pillow 2003, 179). Collectively, our posture of active reflexivity complements growing calls to provide means to assess-rather than replicate-qualitative research by making clear our reflections on and response to positionality throughout the research process (MacLean et al. 2018, 6).

\section{CONCLUSION}

To conclude, being actively reflexive means engaging in the dynamic, continual, and fluid practice of interrogating our own assumptions of positionality, how positionality is being read by others, and the impact of these assessments throughout the research process. Ultimately, this article cautions against the application of a positionality that is essentialist and static. It is a call for deeper and continual reflection on our positionality as researchers. It encourages researchers to adopt a posture of active reflexivity that makes possible thoughtful appraisals and reappraisals of positionality. Doing so can help researchers revise and improve their research strategies and pursue better working relationships, and it may lead to new insights.

\section{ACKNOWLEDGMENTS}

We thank the late Lee Ann Fujii, Peregrine Schwartz-Shea, Dvora Yanow, Robin Turner, David Zarnett, Sarah Wiebe, Eleanor Knott, the editors of $P S$, and two anonymous reviewers for their 
comments on earlier drafts of this article. We also thank Lahoma Thomas for organizing the panel on Race and Fieldwork at the 2016 American Political Science Association Annual Meeting from which this article originated. We dedicate this article to the memory of Lee Ann Fujii.

\section{NOTES}

1. We thank Peregrine Schwartz-Shea and Dvora Yanow for helping us clarify our conceptualization.

2. We thank our anonymous reviewer for this suggestion.

\section{REFERENCES}

Adida, Claire, Karen E. Ferree, Daniel N. Posner, and Amanda Lea Robinson. 2016. "Who's Asking? Interviewer Coethnicity Effects in African Survey Data." Comparative Political Studies 49 (12): 1630-6o.

Berger, Roni. 2015. "Now I See It, Now I Don't: Researcher's Position and Reflexivity in Qualitative Research." Qualitative Research 15 (2): 219-34.

Bernstein, Richard J. 1976. The Restructuring of Social and Political Theory. Philadelphia: University of Pennsylvania Press.

Cammett, Melani. 2013. "Using Proxy Interviewing to Address Sensitive Topics." In Interview Research in Political Science, ed. Layna Mosley, 125-43. Ithaca, NY: Cornell University Press.

Carbado, Devon W. 2013. "Colorblind Intersectionality." Signs: Journal of Women in Culture and Society 38 (4): 811-45

Cramer Walsh, Katherine. 2007. Talking about Race: Community Dialogues and the Politics of Difference. Chicago: University of Chicago Press.

Crenshaw, Kimberle. 1991. "Mapping the Margins: Intersectionality, Identity Politics, and Violence Against Women of Color." Stanford Law Review 43 (6): 1241-99.

D’Arcangelis, Carol Lynne. 2018. "Revelations of a White Settler Woman ScholarActivist: The Fraught Promise of Self-Reflexivity." Cultural Studies Critical Methodologies 18 (5): 339-53.

Davis, Darren W. 1997. “The Direction of Race of Interviewer Effects among African Americans: Donning the Black Mask." American Journal of Political Science 41 (1): 309-22.

Emerson, Robert M., Rachel I. Fretz, and Linda L. Shaw. 2011. Writing Ethnographic Fieldnotes. Chicago: University of Chicago Press.

Fujii, Lee Ann. 2009. Killing Neighbors: Webs of Violence in Rwanda. Ithaca, NY: Cornell University Press.

Fujii, Lee Ann. 2017. Relational Interviewing: An Interpretive Approach to Social Science Research. New York: Routledge.

Glas, Aarie. 2017. "Habits of Peace: Long-Term Regional Cooperation in Southeast Asia." European Journal of International Relations 23 (4): 833-56.

Glas, Aarie. 2018. "African Union Security Culture in Practice: African Problems and African Solutions." International Affairs 94 (5): 1121-38.

Gunaratnam, Yasmin. 2003. Researching "Race" and Ethnicity: Methods, Knowledge and Power. London: SAGE Publications.

Henry, Marsha, Paul Higate, and Gurchathen Sanghera. 2009. "Positionality and Power: The Politics of Peacekeeping Research." International Peacekeeping $16(4): 467-82$. hooks, bell. 2014. Feminist Theory: From Margin to Center, third edition. New York Routledge.

Jacobs, Alan M., and Tim Büthe. 2019. "Transparency in Qualitative Research: An Overview of Key Findings and Implications of the Deliberations." Introduction to Working Paper Series: Qualitative Transparency Deliberations, Working Group Final Reports. Washington, DC: American Political Science Association.

Knott, Eleanor. 2019. "Beyond the Field: Ethics after Fieldwork in Politically Dynamic Contexts." Perspectives on Politics 17 (1): 140-53

MacLean, Lauren M., Elliot Poser, Susan Thomson, and Elisabeth Jean Wood. 2018. "Research Ethics and Human Subjects: A Reflexive Openness Approach." Final Report of Qualitative Transparency Deliberations Working Group I.2. Washington, DC: American Political Science Association.

Oren, Ido. 2015. “Political Science as History: A Reflexive Approach.” In Interpretation and Method: Empirical Research Methods and the Interpretative Turn, second edition, eds. Dvora Yanow and Peregrine Schwartz-Shea, 309-21. Armonk, NY: M. E. Sharpe.

Pachirat, Timothy. 2015. "The Tyranny of Light." Qualitative \& Multi-Method Research Newsletter of the American Political Science Association Organized Section for Qualitative and Multi-Method Research 13 (1): 27-32.

Pillow, Wanda. 2003. "Confession, Catharsis, or Cure? Rethinking the Uses of Reflexivity as Methodological Power in Qualitative Research." International Journal of Qualitative Studies in Education 16 (2): 175-96.

Riessman, Catherine Kohler. 1987. "When Gender Is Not Enough: Women Interviewing Women." Gender and Society 1 (2): 172-207.

Schaffer, Frederic Charles. 2016. Elucidating Social Science Concepts: An Interpretivist Guide. New York: Routledge.

Shehata, Samer. 2006. "Ethnography, Identity, and the Production of Knowledge." In Interpretation and Method: Empirical Research Methods and the Interpretative Turn, second edition, eds. Dvora Yanow and Peregrine Schwartz-Shea, 244-63. Armonk, NY: M. E. Sharpe.

Sherif, Bahira. 2001. "The Ambiguity of Boundaries in the Fieldwork Experience: Establishing Rapport and Negotiating Insider/Outsider Status." Qualitative Inquiry 7 (4): 436-47.

Showden, Carisa R., and Samantha Majic. 2018. Youth Who Trade Sex in the US: Intersectionality, Agency, and Vulnerability. Philadelphia: Temple University Press.

Soedirgo, Jessica. 2018. "Informal Networks and Religious Intolerance: How Clientelism Incentivizes the Discrimination of the Ahmadiyah in Indonesia." Citizenship Studies 22 (2): 191-207.

Syahar Banu, and Jessica Soedirgo. 2019. "How the Positionality of Research Assistants Shapes Knowledge Production.” Washington, DC: Paper presented at the 2019 American Political Science Association Annual Meeting, August 31.

Thomas, Lahoma. 2018. "Dear Political Science, It Is Time for a SELF-REFLEXIVE Turn!" Duck of Minerva, December 18. Available at http://duckofminerva. com/2018/12/dear-political-science-it-is-time-for-a-self-reflexive-turn.html.

Yanow, Dvora. 2006. "Thinking Interpretively: Philosophical Presuppositions and the Human Sciences." In Interpretation and Method: Empirical Research Methods and the Interpretive Turn, eds. Dvora Yanow and Peregrine Schwartz-Shea, 5-25. Armonk, NY: M. E. Sharpe.

Yanow, Dvora. 2014. "Interpretive Analysis and Comparative Research." In Comparative Policy Studies: Conceptual and Methodological Challenges, eds. Isabelle Engeli and Christine Rothmayr Allison, 131-59. Basingstoke, UK: Palgrave Macmillan.

Yanow, Dvora, and Peregrine Schwartz-Shea (eds.). 2006. Interpretation and Method: Empirical Research Methods and the Interpretive Turn. Armonk, NY: M. E. Sharpe. 